\title{
A articulação entre a EDUCAÇÃO BÁSICA e o ensino superior: contribuições dos MESTRADOS PROFISSIONAIS EM EDUCAÇÃO
} Articulation between basic and higher education: contributions of professional masters in education

\author{
Francine de Paulo Martins Lima', Helena Maria Ferreira², Marco Antônio Villarta-Neder ${ }^{3}$
}

\begin{abstract}
Resumo
Este artigo elege como objeto de discussão um dos objetivos precípuos dos mestrados profissionais em educação, qual seja, a articulação entre o ensino superior e a educação básica. $O$ objetivo consiste em inventariar as contribuições propiciadas pelo Programa de Mestrado Profissional em Educação (PPGE) da Universidade Federal de Lavras (MG) para a atuação dos egressos na educação básica. O trabalho apresenta as especificidades das propostas dos mestrados profissionais em educação, discute os processos de articulação entre ensino superior e educação básica e analisa o contexto dos processos de formação de professores e de constituição de sujeitos. $\mathrm{O}$ trabalho apresenta uma análise das percepções dos egressos acerca da efetividade das ações formativas para os diversos campos de atuação de professores da educação básica. As discussões empreendidas demonstraram que a articulação entre ensino superior e a educação básica ainda constitui um desafio, uma vez que as contribuições ainda demandam um tratamento que permita a criação de estratégias para uma maior visibilidade das ações/pesquisas desenvolvidas e a sistematização das percepções dos egressos. Nesse sentido, a contribuição deste trabalho se consubstancia na provocação de uma reflexão sobre a efetividade dos Mestrados Profissionais para uma formação para a docência e para a gestão escolar na educação básica, evidenciando um posicionamento que considera que o projeto e as ações formativas dessa modalidade se constituem como práticas sociais, que, por sua vez, promovem a constituição de sujeitos, propiciam a compreensão de processos educativos, ampliam as bases epistemológicas e fortalecem a aproximação entre agências educativas e agentes formadores.
\end{abstract}

Palavras-chave: Mestrados profissionais; Formação de professores; Educação básica; Egressos.

\begin{abstract}
This article chooses as object of discussion one of the main objectives of the professional masters in education, that is, the articulation between higher education and basic education. The objective is to inventory the contributions made by the Professional Master's Program in Education (PPGE) of the Federal University of Lavras (MG) for the performance of the graduates in basic education. This paper presents the specificities of the professional masters' proposals in education, discusses the processes of articulation between higher education and basic education, and analyzes the context of the processes of teacher training and the constitution of subjects. This work presents an analysis of the students' perceptions about the effectiveness of the formative actions for the different fields of action of teachers of basic education. The discussions have shown that the articulation between higher education and basic education is still a challenge, since the contributions still require a treatment that allows the creation of strategies for a greater visibility of the actions / researches developed and the systematization of the students' perceptions. In this sense, the contribution of this work consists in provoking a reflection on the effectiveness of the Professional Masters for a formation for teaching and for the school management in the basic education, evidencing a position that considers that the project and the formative actions of this modality are constitute social practices, which, in turn, promote the constitution of subjects, facilitate the understanding of educational processes, broaden the epistemological basis and strengthen the approximation between educational agencies and training agents.
\end{abstract}

Keywords: Professional Masters; Teacher training; Basic education; Egressos.

\footnotetext{
${ }^{1}$ Universidade Federal de Lavras - https://orcid.org/0000-0002-9646-8235

2 Universidade Federal de Lavras - https://orcid.org/0000-0002-8749-5426

${ }^{3}$ Universidade Federal de Lavras - https://orcid.org/0000-0003-3857-3720

Contato com autor: francinedepaulo@uol.com.br
} 


\section{INTRODUÇÃO}

Problematizar questões ligadas às propostas dos mestrados profissionais em educação constitui a assunção de um posicionamento discursivo acerca desse projeto de formação, uma vez que esse contexto emana peculiaridades que evocam pressupostos epistemológicos e axiológicos sobre o papel da pós-graduação e de seus efeitos para a formação de sujeitos-professores e para a análise fundamentada das práticas pedagógicas.

Nessa direção, elegemos, neste artigo, como objeto de discussão a articulação entre os cursos de mestrados profissionais e a escolas de educação básica, assumindo a posição de que os mestrados profissionais apresentam especificidades formativas e que essas especificidades devem ser sobressaltadas a despeito das meras críticas de arremedo da modalidade acadêmica.

Isso implica, no nosso entendimento, uma (re)significação do processo de formação, em que se conceba esse processo como um projeto dialógico. Para que esse projeto se efetive é necessário considerar a articulação com os acontecimentos da vida, para sobre eles constituir compreensões e construir interpretações e estratégias de atuação. Nesse viés, consideramos que a formação profissional demanda dois movimentos quase concomitantes de problematização e de compreensão. A problematização se realiza na prática, nos questionamentos sobre o papel do professor, sobre as demandas da escola, dos professores, dos alunos, sobre a função social dos conteúdos trabalhados e habilidades buscadas, sobre a efetividade dos processos de gestão etc. Já a compreensão abarca as informações sobre o contexto escolar até as considerações de natureza mais ampla, tais como lugares sociais, ideologias, história cultural, etc. Para esse movimento, a formação profissional demanda um novo desenvolvimento profissional, que, nas palavras de André (2016, p.32), baseia-se na concepção de professor pesquisador, que, por meio e a partir da formação poderá "compreender as teorias implícitas na ação, fundamentá-las, revisá-las e reconstruí-las. Isso exige um aprendizado de leitura crítica da prática, de análise fundamentada da situação para entendê-la e encontrar caminhos para reestruturá-la, tornando-a melhor".
Nessa perspectiva de formação, buscamos neste artigo discorrer sobre algumas percepções dos egressos - coletadas em 2019 - acerca das contribuições propiciadas pelo Programa de Pós-Graduação em Educação (PPGE), que em sua modalidade profissional, apresenta como um de seus objetivos precípuos, a busca de articulação entre universidade e educação básica.

Para fundamentar a nossa discussão, consideramos relevante contextualizar, ainda que de modo incipiente, as especificidades dos Programas de Mestrado Profissionais em educação, destacando seus compromissos formativos, éticos e políticos. Além disso, buscamos teorizar também sobre a questão da articulação entre ensino superior e educação básica, evidenciando avanços e desafios inerentes a esse processo de interlocução. Soma-se a essas questões, ainda, uma reflexão sobre o contexto formativo de professores e a constituição de sujeitos. A partir da teorização empreendida, serão analisados excertos dos depoimentos de egressos do PPGE, que evidenciaram as contribuições das atividades formativas vivenciadas durante o curso para a atuação docente.

Espera-se que este artigo possa contribuir para uma reflexão acerca das potencialidades dos programas de mestrado profissional, com vistas a favorecer a visibilidade das ações realizadas nessa modalidade e propiciar a construção de uma identidade capaz de evidenciar as peculiaridades desse importante projeto formativo.

\section{MESTRADOS PROFISSIONAIS EM EDUCA- ÇÃO: PECULIARIDADES FORMATIVAS E A CONSTITUIÇÃO DE SUJEITOS}

Mesmo reconhecendo que os mestrados profissionais em educação (MPE) ${ }^{1}$ ainda encontram-se em

1 Os Mestrados Profissionais em Educação (MPE) constituem uma modalidade de oferta da pós-graduação stricto sensu no Brasil, ou seja, são um tipo de formação que se dá para estudantes egressos da graduação, oferecida por instituições de ensino superior devidamente credenciadas pelo Ministério de Educação (MEC) e recomendada pela Coordenação de Aperfeiçoamento de Pessoal de Nível Superior (CAPES). Eles possuem características próprias que os diferenciam dos mestrados acadêmicos (MA). (FIALHO; HETKOWSKI, 2017, p. 20) 
fase de consolidação, em função dos desafios enfrentados para a constituição de uma identidade própria e dos enfrentamentos de rompimento com uma cultura histórica construída pela tradição dos mestrados acadêmicos, podemos constatar que os fundamentos para a sua criação explicitam uma clareza que nos possibilita distinguir as duas modalidades.

Caracterizando essa distinção, Fialho e Hetkowski (2017, p. 21) elucidam que

A pós-graduação profissional pretende responder pela formação de alto nível para profissionais de todas as áreas do saber não necessariamente interessados na carreira acadêmica (ênfase assumida pelos programas acadêmicos, mestrados e doutorados). 0 ambiente profissional ou mundo do trabalho dos pós-graduandos é importante eixo formativo dos estudantes ou acadêmicos. Especificamente na educação, destacam-se problemáticas, especialmente em relação à formação de professores (notadamente no âmbito das licenciaturas) e à gestão educacional e escolar, no âmbito dos sistemas de ensino. Assim, os MPE vão se constituindo como espaços de aplicação e geração de processos formativos e de investigação, de natureza teórica e metodológica, que se abrem perante o extenso campo de atuação de professores, gestores e profissionais da educação, fortalecidos pela aproximação entre a educação superior e a educação básica.

Essa citação nos permite destacar questões basilares que caracterizam a formação de professores no âmbito dos mestrados profissionais. Essas questões podem ser traduzidas a partir das seguintes indagações: a) O que significa "responder pela formação de alto nível para profissionais de todas as áreas"?, b) Que estratégias os Programas podem utilizar para viabilizar a efetiva aproximação das ações propostas com "o ambiente profissional ou mundo do trabalho dos pós-graduados"?, c) Como os Programas podem atuar para o enfrentamento das problemáticas relacionadas à formação de professores e à gestão educacional e escolar"?, d) Qual é a relevância da aproximação entre a educação superior e a educação básica para a consolidação dos MPE? A própria citação nos oferece uma possibilidade de resposta à medida em que afirma que os MPE se constituem como espaços de aplicação e geração de processos formativos e de investigação, que articulam teoria e prática e que viabilizam o diálogo entre a as duas modalidades de ensino: educação superior e educação básica.

Para nós, a citação de Fialho e Hetkowski (2017) nos apresenta como demasiadamente provocativa. Por isso, consideramos relevante refletir sobre alguns pontos abordados pelas autoras, e, assim, poder contribuir para um debate sobre os mestrados profissionais.

\section{FORMAÇÃO DE SUPERIOR QUALIDADE}

Inicialmente, cabe salvaguardar as críticas relacionadas aos tempos e espaços de formação no âmbito da pós-graduação stricto sensu, em nível de mestrado, seja na modalidade acadêmica, seja na modalidade profissional, que são tomadas como argumentos que afetam uma formação de qualidade. Nessa modalidade (profissional), entretanto, os efeitos desse tempo-espaço podem ter impactos ainda maiores.

As críticas sobre o tempo/espaço de formação incidem sobre a determinação de prazo para conclusão do Curso (24 ou 30 meses) e sobre a impossibilidade de participação dos professores em atividades na Universidade ou de desenvolvimento de projetos longitudinais nas escolas de educação básica, uma vez que, recorrentemente, o profissional atua em mais de um cargo na docência/gestão, sem direito à licença para capacitação, o que, notadamente, afeta a qualidade do percurso formativo e a participação em atividades que integram a formação.

No entanto, a especificidade de configuração dos mestrados profissionais permite o incentivo à criação de produtos diversificados, o que representa uma estratégia para assegurar uma formação de superior qualidade, dadas as possibilidades de diálogos entre a formação e a atuação. De acordo com a Portaria Normativa/Capes n. 17 (2009),

O trabalho de conclusão final do curso poderá será apresentado em diferentes formatos, tais como dissertação, revisão sistemática e aprofundada da literatura, artigo, patente, registros de propriedade intelectual, projetos técnicos, publicações tecnológicas; desenvolvimento de aplicativos, de materiais didáticos e instrucionais e de produtos, processos e técnicas; produção de pro- 
gramas de mídia, editoria, composições, concertos, relatórios finais de pesquisa, softwares, estudos de caso, relatório técnico com regras de sigilo, manual de operação técnica, protocolo experimental ou de aplicação em serviços, proposta de intervenção em procedimentos clínicos ou de serviço pertinente, projeto de aplicação ou adequação tecnológica, protótipos para desenvolvimento ou produção de instrumentos, equipamentos e kits, projetos de inovação tecnológica, produção artística, sem prejuízo de outros formatos, de acordo com a natureza da área e a finalidade do curso, desde que previamente propostos e aprovados pela CAPES.

As possibilidades de construção de produtos diferenciados de uma dissertação, tal como é exigido nos mestrados acadêmicos, é um aspecto sinalizador das especificidades dos mestrados profissionais, que podem viabilizar não somente o enfrentamento dos problemas da escola, mas também possibilidades de desenvolvimento profissional, seja por meio de reflexões sobre os fundamentos epistemológicos e axiológicos da educação, seja por meio de análise das práticas pedagógicas. Desse modo, depreendemos que a aproximação com o espaço de trabalho é um importante elemento para a garantia da qualidade dos processos formativos.

Ainda no âmbito da qualidade do processo formativo, podemos considerar que a avaliação dos cursos de pós-graduação por parte da CAPES representa uma garantia de atendimento aos requisitos básicos para uma sistematização dos processos e dos resultados das ações empreendidas pelas universidades, o que, de certo modo, viabiliza um acompanhamento dos cursos. Assim, a ficha de avaliação proposta para os MPE contempla três quesitos basilares: Programa, Formação e Impacto na Sociedade. Segundo as orientações feitas pelas comissões avaliadoras da CAPES,

No quesito Programa, pretende-se avaliar o funcionamento, estrutura e planejamento do programa de pós-graduação em relação ao seu perfil e seus objetivos. Quanto ao quesito Formação, a análise abrangerá aspectos como qualidade das teses, dissertações, produção intelectual de alunos e professores e das atividades de pesquisa, bem como a avaliação do egresso. Já em relação ao Impacto na Sociedade, a avaliação vai verificar o caráter inovador da produção intelectu- al, os efeitos econômicos e sociais do programa, internacionalização e visibilidade. (BRASIL, CAPES, 2019)

Esses indicadores sinalizam uma organização estrutural que permitem o estabelecimento de políticas públicas para os investimentos na Pós-graduação, possibilita uma aferição dos resultados das ações dos diferentes Programas. No entanto, ressaltamos que uma avaliação institucional per si não consegue subsumir a dimensão qualitativa de modo completo, mas há outros indicadores que são estabelecidos pelas instituições e pelos Programas em si, o que viabiliza uma avaliação cíclica dos processos de organização acadêmica e dos produtos intelectuais.

Além dessas questões, merecem destaque a sistematização e a socialização de estudos que perscrutam as especificidades dos mestrados profissionais, o que tem possibilitado "o fortalecimento de bases epistêmicas no campo da pesquisa e da formação, por contemplar relações entre educação superior e educação básica." (FIALHO; HETKOWSKI, 2017, p. 21).

Desse modo, podemos considerar que a formação de superior qualidade, proposta pelos mestrados profissionais, está atrelada à finalidade de "levantar, identificar, estudar, interpretar e apontar caminhos, em suma, construir inteligência sobre a formação profissional." (ROMÃO; MAFRA, 2016, p. 17).

\section{APROXIMAÇÃO DA FORMAÇÃO DOCENTE COM A ATUAÇÃO PROFISSIONAL}

No que tange à efetiva aproximação das ações propostas com "o ambiente profissional ou mundo do trabalho dos pós-graduados", de modo mais específico, com a educação básica, merece atenção a necessidade de articulação entre "a estrutura curricular objetiva, coerente com as finalidades do curso e consistentemente vinculada à sua especificidade, enfatizando a articulação entre conhecimento atualizado, domínio da metodologia pertinente e aplicação orientada para o campo de atuação profissional." (BRASIL, CAPES, 2019). Assim, a formação dos egressos de um curso de mestrado profissional na área de educação demanda um investimento epistemológico 
que possibilite uma visão ampliada do processo educativo, de modo a problematizar concepções, crenças, metodologias, conteúdos, recursos didáticos e a própria identidade docente. Nesse contexto, o desenvolvimento docente impõe processos formativos que possibilitem uma reflexão sobre autonomia profissional, sobre o propósito político e as especificidades da atuação docente, sobre a escola como locus da ação profissional e de suas motivações, inquietações e problemas. (CAMPOS, GUÉRIOS, 2017).

Nessa especificidade, estão articulados os percursos históricos da educação, os pressupostos filosóficos que fundamentam os princípios axiológicos, os fundamentos teóricos e metodológicos das áreas específicas, as políticas públicas, as discussões sobre gestão educacional/escolar, os constructos teóricos nos quais se baseiam as discussões sobre a constituição dos sujeitos.

Sobre essas questões, Imbernón (2016, p. 51) pontua que "[...] não será possível enfrentar o futuro sem ensinar e aprender a complexidade de ser cidadão e as diversas sensibilidades nas quais se materializa: democrática, social, solidária, igualitária, intracultural e relativa ao meio ambiente".

Nesse âmbito, ao refletirmos sobre as estratégias que propiciem uma formação mais ampliada, merece destaque a diversidade de ações, tais como: promoção de eventos diversificados (na condição de ouvintes ou ministrantes), incentivo à participação dos estudantes em grupos de estudos/pesquisa, incentivo à produção de textos acadêmicos (resenhas, ensaios, relatos, artigos, resumos, resumos expandidos, capítulos etc), problematização de questões educacionais no âmbito das disciplinas, criação de espaços para socialização das pesquisas, articulação com escolas de educação básica entre outras. A diversidade de ações, além da promoção do diálogo entre os pares, pode favorecer o acesso à uma formação mais qualificada, na medida em que várias questões relacionadas à docência/gestão são problematizadas.

No entanto, não basta a instituição formadora investir na diversidade de ações. Apoiando-nos em Gatti (2013), podemos considerar que os profissionais da educação constroem suas práticas educativas em suas formações diversas e em seu exercício docente. Nesse contexto, há um sujeito, que se constitui nas/pelas interações.

Isso nos possibilita a considerar que a prática educativa, é, por constituição, uma prática social, já que as práticas pedagógicas são intencionais - configuram-se como um projeto em que estão envolvidos posicionamentos, modos de dizer e de fazer. Os percursos formativos pressupõem escolhas, são dinamizados nas/a partir de interações, que desencadeiam uma (re)significação dos lugares enunciativos por parte dos sujeitos que delas participam. Nesse âmbito, a implicação dos diferentes sujeitos nas interações desencadeia uma relação conflituosa entre discursos, saberes e práticas, mas que são, substancialmente, relevantes para possibilitar que compreensões contraditórias sejam refletidas na relação teoria-prática e nas bases epistemológicas que fundam o processo formativo. O pensar e o agir "não existem no vácuo, no contexto escolar micro, mas é um agir inserido em um contexto macro, em relações enunciativas, situadas em contextos sócio-históricos das experiências dos participantes." (MAGALHÃES; NININ; LESSA, p. 2014, p. 132)

Pensar a formação docente no âmbito dos programas de mestrado profissional implica considerar a natureza das interações, o estatuto das inquietações, a constituição do sujeito-professor. Segundo Bakhtin (2011, p. 294-295),

em cada época, em cada círculo social, em cada micromundo familiar, de amigos e conhecidos, de colegas, em que o homem cresce e vive, sempre existem enunciados investidos de autoridade que dão o tom, como as obras de arte, ciência, jornalismo político, nas quais as pessoas se baseiam, as quais elas citam, imitam seguem. E cada época e em todos os campos da vida e da atividade, existem determinadas tradições, expressas e conservadas em vestes verbalizadas: em obras, enunciados, sentenças, etc. Sempre existem essas e aquelas ideias determinantes dos "senhores do pensamento" de uma época verbalmente expressas, algumas tarefas fundamentais, lemas, etc. [...] Nosso discurso, isto é, todos os nossos enunciados (inclusive as obras criadas) é pleno de palavras dos outros, de um grau vário de alteridade ou assimilabilidade, de um grau vário de aperceptibilidade e de relevância. Essas palavras dos outros 
trazem consigo a sua expressão, o seu tom valorativo que assimilamos, reelaboramos, e reacentuamos.

Assim, podemos considerar que as teorias e as discussões realizadas nas diferentes atividades próprias de um curso de mestrado profissional serão (re) significadas de acordo com o contexto, em uma cadeia dialógica, que é constituída por/a partir de uma postura de responsividade ativa, que pode reforçar, enriquecer, contradizer ou definir determinados discursos (BAKHTIN, 2011).

A noção de "atitude ativa" nos ajuda a pensar o lugar discursivo ocupado pelos alunos de um mestrado profissional. A egrégia discussão sobre articulação entre teoria e prática é aqui evidenciada. Se pensarmos que, tal como propõe Bakhtin (2011), o sujeito nunca é passivo diante do discurso do outro, ele não recebe passivamente nada do que lhe é apresentado, a mobilização para uma atitude ativa por parte dos alunos pode representar uma possibilidade de (re)significação do processo formativo. Esses alunos-sujeitos poderão reforçar, enriquecer, contradizer ou definir determinados discursos, conforme citado anteriormente. Nesse âmbito, poderão desconstruir estereótipos, sistematizar saberes e refletir sobre novas práticas. Desse modo, podemos reiterar que a posição assumida pelos professores em formação poderá interferir, notadamente, na qualidade dessa formação. São os tensionamentos e as convergências dos/nos discursos que, em movimento recursivo, tal como mencionado por Gatti (2013) fundam a articulação entre ensino superior e a escola de educação básica.

Complementando o exposto, Martins, Lucas e Mirandola (2016, p. 117) pontuam que "a articulação entre escola e universidade permite não só a constituição da profissionalidade, como também a reconfiguração da IES e da escola pública, numa perspectiva de ação colaborativa na formação do professor."

Nesse movimento dialógico e dialético, o processo formativo se configura como uma (inter)ação, que envolve sujeitos em contínua constituição. Nesse âmbito, professores formadores e professores em formação produzem conhecimentos, problematizam saberes, constroem percursos e vivenciam experiências sobre aprender e sobre ensinar, de modo reflexivo.
ENFRENTAMENTO DAS PROBLEMÁTICAS RELACIONADAS À FORMAÇÃO DE PROFESSORES E À GESTÃO EDUCACIONAL E ESCOLAR

Embora a questão do enfrentamento das problemáticas relacionadas à formação de professores e à gestão educacional e escolar se revista de complexidade, consideramos que admitir que a profissão docente é um constante (re)fazer-se, pois assim são os sujeitos sociais, pode favorecer que a percepção de que a formação docente se constitui como um evento. A aula (ou outra atividade formativa), seja ela na universidade, seja ela na escola de educação básica "terá profundas relações com as novas formas dos conhecimentos: sempre parciais, locais, incertos. Talvez nossa grande aprendizagem com os novos paradigmas científicos e culturais seja a aprendizagem das instabilidades" (GERALDI, 2013, p. 92).

Nesse âmbito, cada momento formativo, tomado como um acontecimento, exigirá do professor o conhecimento dos saberes produzidos historicamente relativos à área de conhecimento ou à educação, no entanto, esses saberes não são suficientes. O professor, no contexto das novas tecnologias e as mudanças sociais, econômicas e culturais, não tem todas as respostas. Geraldi (2013, p. 95) ressalta que o professor do futuro, considerando a nova identidade demandada pela contemporaneidade, "não é a do sujeito que tem respostas que a herança cultural já deu para certos problemas, mas a do sujeito capaz de considerar o seu vivido, de olhar o aluno como um sujeito que também já tem um vivido, para transformar o vivido em perguntas."

Complementando essa questão, Gatti (2013, p. 54) considera que

práticas geram teorizações e teorizações geram práticas, em movimento recursivo. Práticas são fatos culturais e assim precisam ser significadas. Essa relação dialética é quebrada nas nossas estruturas universitárias e curriculares, herdadas de uma concepção de ciência positivada, em que as abstrações imperam como tópicos em vasos não comunicantes: conhecimento "da ciência" isolado do "conhecimento pedagógico-educacional", este sempre considerado como de menor valor. A escola tem seu eixo em práticas educativas que, por sua vez, têm seus fundamentos 
em perspectivas filosófico-sociais e bio-psicológicas, e se constituem nos meios pelos quais formamos as novas gerações abrindo-lhes possibilidades de avançar na construção do bem comum, de produzir recriações da cultura e da ciência. Os profissionais da educação constroem suas práticas educativas em suas formações diversas e em seu exercício docente.

Desse modo, pensar a formação docente sob a perspectiva da incompletude, de inacabamento pressupõe um olhar crítico não apenas para as ações formativas, mas para os modos de apropriação dos conhecimentos por parte dos pós-graduandos, para os modos de exercer a docência e, notadamente, para as interações que integram as relações entre os sujeitos. Conceber a formação nessa perspectiva implica considerar as intersubjetividades, a autoria, a interlocução e os posicionamentos enunciativos como constitutivos de sujeitos e saberes. O professor, independente da área do conhecimento, é um profissional da palavra, do diálogo, um sujeito respondente e responsável pelo seu ato e responsivo nas ações. Para Sobral (2008), essa concepção implica considerar o sujeito como um sujeito ativo e relacional, que ocupa um lugar ético no mundo, ou seja, de resposta à vida.

Nesse sentido, retomando a questão da aproximação com o ambiente profissional ou mundo do trabalho dos pós-graduados, é válido considerar que o mundo teórico se obtém por uma abstração e por um evento vivido na vida, em sua totalidade, que não pode ser transcrito em termos teóricos, porque perderia seu caráter de evento único e irrepetível. Assim, a construção de conhecimentos demanda um ato responsivo, em que articula a compreensão das especificidades das teorias e das práticas. Desse modo, o mundo da cultura - teorias - se constitui pelas generalidades e o mundo da vida - práticas se constitui pelas particularidades, pelas subjetividades.

No âmbito educacional, as teorias desenvolvidas sobre a prática docente buscam generalizar aspectos dessa prática, encontram alguma regularidade, entretanto, segundo entendimento de Catarino, Barbosa-Lima, Queiroz (2015, p. 837-838), com os quais concordamos, uma teoria nunca dará conta de "ser" a própria prática, pois cada prática é singular, é única e nem pode ser reproduzível. Dessa maneira, o discurso de um professor sobre sua prática, por exemplo, pode carregar um tom de generalidade, tentar externar o desejo de realização de uma determinada prática, enquanto sua prática em sala de aula sempre será única e, nem sempre, acompanhará ou será completamente fiel ao discurso sobre ela. Concordando com Tardif e Lessard (2005, p. 46), a docência se apresenta como "um trabalho fortemente contextualizado, concreto, posicionado (SCHÖN, 1983), marcado principalmente pelas contingências situacionais". Além disso, nem sempre, os objetivos traçados pelos professores para justificar seus atos correspondem às condições de ação: "os atores não fazem sempre o que dizem fazer e não dizem necessariamente, inclusive a si mesmos, o que fazem efetivamente" (TARDIF, 2002, p. 204).

Nessa direção, ao problematizarmos a relação teoria e prática, parece-nos possível considerar que a prática que se efetiva no âmbito das atividades de um curso de mestrado profissional pode ser concebida a partir elementos comuns com outros atos e, por isso, podem fazer parte de um ato como "categoria englobante" (SOBRAL, 2008), mas não pode sucumbir à generalização. A atividade docente, segundo Catarino, Barbosa-Lima, Queiroz (2015, p. 839 $-840)$,

é marcada pela eclosão desses eventos irrepetíveis. Somente o que é constante não faz a docência intelectual, é necessário o irrepetível, o evêntico, o único. É o que a faz dinâmica, não estagnada, pois é nesse sentido que o professor, também sujeito da ação, passa a se perceber único e a se posicionar, assumindo, então, a responsabilidade: se eu sou insubstituível, devo realizar minha unicidade (BAKHTIN, 2010). Cada sujeito ocupa um lugar irrepetível e insubstituível no mundo e, por isso, na perspectiva de Bakhtin, o sujeito deve ser responsável por seus atos e ter obrigação ética com relação ao outro. Ser - existir - na vida significa, então, agir, enunciar. Só eu posso realizar minha singularidade. Isso não quer dizer que o sujeito está sozinho no mundo: sempre existe o outro centro axiológico - o outro - que participa do processo dialógico, que baliza o agir responsável do sujeito e para quem o sujeito se dirige. [...] O professor age pensando no outro, vários "outros". Cada outro é constituído pelo seu centro de valores - axiológicos - que se contrapõem e geram a realização de atos concretos. Não 
podemos deixar de apontar que as tensões do professor se baseiam também nos embates com o outro.

São esses eventos únicos, irrepetíveis que constituem os sujeitos-professores, seja no desenvolvimento profissional, seja na atuação docente. Nessa travessia entre formação docente e atuação profissional, entre ensino superior e educação básica é que se efetiva a consolidação de saberes que articulam o mundo da cultura - saberes teóricos e o mundo da prática - saberes da experiência, entre o mundo do dizer e o mundo do fazer, de modo indissociável e sempre em construção.

\section{ANÁLISE DOS DEPOIMENTOS}

Para enriquecer as discussões sobre os mestrados profissionais, consideramos relevante discorrer sobre três depoimentos que desvelam as percepções de egressos do Programa de Pós-graduação em Educação - modalidade profissional - da Universidade Federal de Lavras. No âmbito de uma pesquisa que acolhe informações e percepções de egressos, selecionados uma questão para discussão: Quais foram/ são as contribuições do Mestrado Profissional em Educação para a sua atuação em escolas de educação básica? O questionário foi encaminhado para os egressos do PPGE, por meio de um convite, acompanho de um link para acesso a google.forms.

Em função da quantidade de participantes, selecionamos enunciados, que no nosso entendimento, apresentava uma visão mais ampliada das contribuições do PPGE. Entre os muitos aspectos presentes nesses depoimentos que apontam para essa relação dinâmica entre universidade e escola e indiciam o percurso formativo do Mestrado Profissional em Educação, selecionamos três.

Para proceder à análise, vamos, inicialmente, tomar o conceito de enunciado. Para os autores do Círculo de Bakhtin, o enunciado não é somente um dizer, mas um processo de dizer, que conjuga o ato e o conteúdo do dizer, os sujeitos que dele participam e o acontecimento que os congrega. Para Volóchinov, qualquer "[...] enunciação, também aquela escrita, completa, responde a alguma coisa e é orientada para uma resposta." (VOLÓCHINOV, 2013, p. 118).
Em outra obra o mesmo autor destaca:

Desse modo, cada elemento semântico isolável do enunciado, assim como o enunciado em sua totalidade, é traduzido por nós para outro contexto ativo e responsivo. Toda compreensão é dialógica. A compreensão opõe-se ao enunciado, assim como a réplica opõe-se a outra no diálogo. A compreensão busca uma antipalavra à palavra do falante. (VOLÓCHINOV, 2017, p. 232).

Assim, entendemos que cada dizer responde a outro e suscita um dizer e(nquanto) compreensão. Tomando os dizeres dos depoimentos como enunciados, a partir dessa perspectiva, podemos analisar mais detidamente os aspectos que estamos destacando na discussão sobre o mestrado profissional em Educação.

O primeiro enunciado que vamos discutir refere-se ao depoimento do egresso 1 , que diz que "Pensar sobre identidade docente mudou completamente o modo de ser professora" (egresso 1). O interessante desse enunciado é que tanto na forma, quanto na temática, assume uma relação indissociável entre teoria de prática. Os verbos "pensar" e a expressão "modo de ser" estão ligados pelo verbo "mudar". É um relato de um movimento que, no/por meio do enunciado evidencia um processo dialógico do sujeito. Alude a um sujeito anterior, que, no próprio ato de pensar sobre a identidade docente transforma-se em outro. Cabe observar que o objeto desse pensar é uma prática que vai constituindo o sujeito professor (identidade docente é algo construído). A visão pontual do que o docente veio a se tornar resulta, inevitavelmente, de um percurso profissional, de uma prática de agir no mundo como docente. Esse sujeito anterior vai se transformando, como relata o enunciado, no modo de ser, ou seja, axiologicamente. Temos, então, uma relação dinâmica entre a teoria (os textos, as discussões, as leituras), a epistemologia (a reflexão sobre a natureza do conhecimento e do sujeito cognoscente), a axiologia (na mudança de posicionamento sobre si, sobre a profissão e sobre o mestrado) e a metodologia (modo de ser alude a maneira por meio das quais esse sujeito-professor atua em sua prática profissional). 
Na figura abaixo, sintetizamos essas relações:

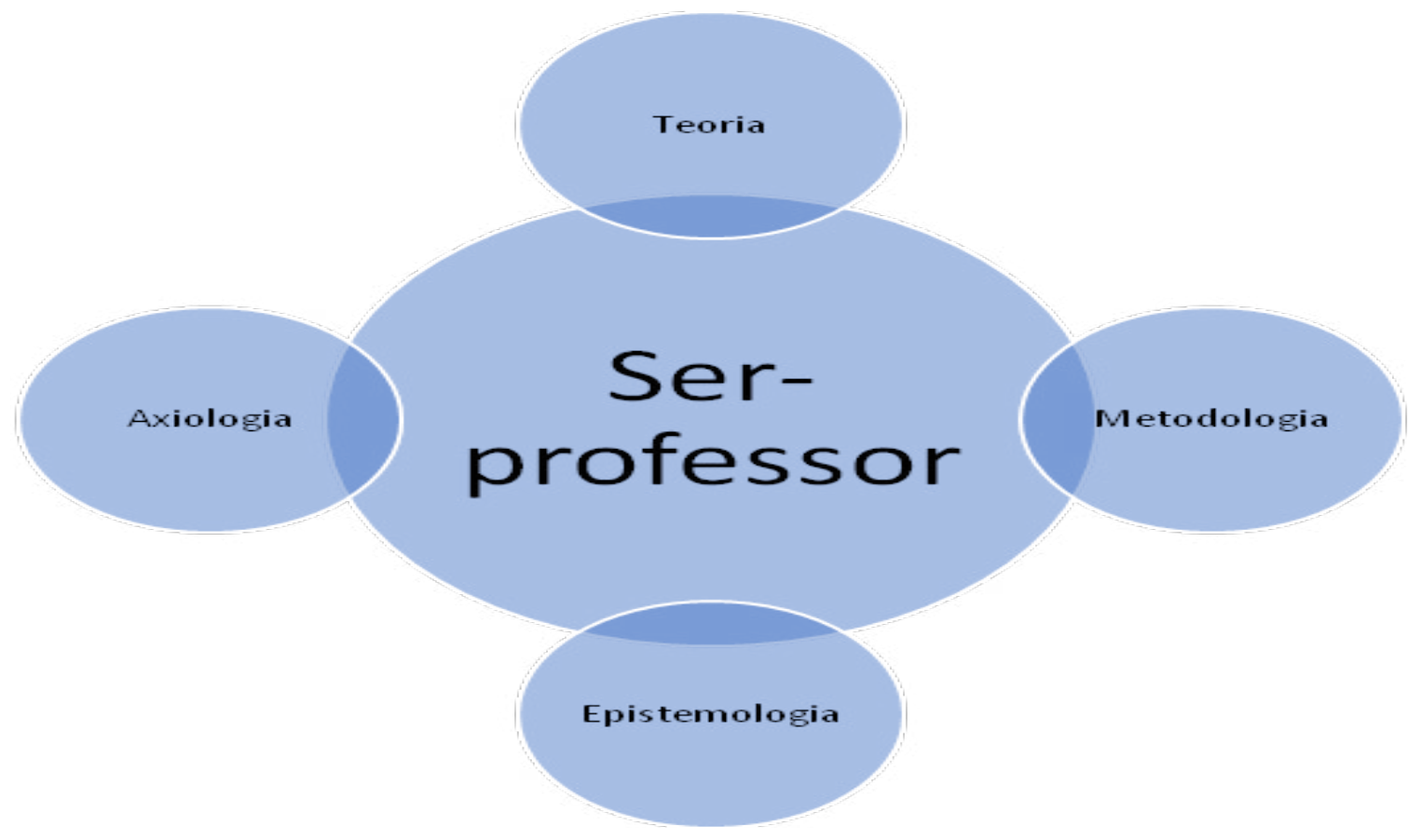

Figura 1 - Instâncias do ser-professor na relação teoria/prática. Autoria própria.

Uma implicação importante dessas dimensões inter-relacionadas é exatamente uma concepção dinâmica entre teoria e prática. Assim, para que os Mestrados Profissionais possam satisfazer a condição de qualidade, sem abandonar sua vocação de olhar para a prática profissional, não só enfrentando-a como objeto de análise, mas construindo fazeres que a ressignifiquem, importa considerar que refletir é um fazer, que os fazeres são, em contrapartida, resultados de concepções, que cada fazer/dizer é revestido de valores que o sustentam, que subjazem a eles. $E$, finalmente, que há um caminho, uma metodologia, não como lista de procedimentos estanques, mas como consequência das crenças, visões e tomadas de posição que essa relação teoria-prática institui na formação dos alunos. seguinte:

O segundo enunciado que analisaremos é o

Aprendi a importância de ser um professor pesquisador, a valorar a importância das concepções para o desenvolvimento do fazer educativo, a ter curiosidade sobre as formas de se pensar a educação em diferentes épocas e aprendi também a importância da dimensão afetiva no exercício docente. (Egresso 2)
Nesse enunciado, o egresso 2 incorpora uma concepção, que é a de "professor pesquisador". Há, aqui, uma dupla dimensão. Uma, na acepção de Paulo Freire, de um professor, pesquisador de sua própria prática, e outra, a da vivência, no processo acadêmico do Mestrado Profissional, de uma atenção mais intensa para com as concepções. Nota-se que o egresso interliga as noções teóricas (concepções) ao "desenvolvimento do fazer educativo". A questão das concepções incide sobre dois aspectos de formação. O primeiro é o de investigar o percurso teórico-epistemológico que subjaz a essas concepções. 0 segundo é, no interior do próprio processo cognitivo-acadêmico do aluno, relacionar essas concepções a suas práticas, suas vivências. Em seguida, o aluno, em seu depoimento, menciona a curiosidade sobre formas de pensar em diferentes épocas. A dimensão do enunciado enquanto movimento que se relaciona ao que the antecede e se move para uma resposta, para uma compreensão é nitidamente percebido aqui. A curiosidade é uma compreensão responsiva ativa, como diria Bakhtin, em relação às concepções que identificou e com as quais (não) se identificou.

Por último, o egresso menciona como apren- 
dizagem sua, a "importância da dimensão afetiva no exercício docente". Podemos dizer que essa dimensão afetiva pode ser traduzida por uma perspectiva ética de responsabilizar-se por quem este profissional está sendo e por quem os seus alunos são, em cada ato pedagógico, em sala de aula. Bakhtin, em Para uma filosofia do ato responsável, diz que cada sujeito se constitui dentro de uma arquitetônica intersubjetiva. Nessa arquitetônica, cada ato é uma tomada de posição, um ato responsável desse sujeito, já que só me constituo a partir da visão de fora, do lugar (do) outro, a partir do qual posso me ver por inteiro. E, como outro do meu outro, também sou responsável por esse lugar que permite a ele enxergar-se, atribuir-se sentido.

Ver-se nessa dimensão afetiva é mais do que envolver-se emocionalmente pela atividade profissional docente. É responsabilizar-se pela dimensão humana do exercício profissional, com a necessária reflexão sobre as concepções, caminhos, valores, não desvinculando-os de um para quem. Lembrar-se do outro, da responsabilidade para com esse outro, é responsabilizar-se pelo próprio ofício. Novamente, podemos ancorar essa discussão em Bakhtin: "Dos meus olhos olham os olhos alheios" (BAKHTIN, 2019, p. 51). O compromisso ético com esses olhos alheios, com a perspectiva alheia que determina a reflexão de qualidade sobre o fazer profissional. Esse pode e deve ser um critério para auferir a qualidade da formação contínua(da) desse profissional. Ao perguntar-se sobre como esse outro, com esse olhar alheio vai responder como compreensão às teorias e às práticas que o profissional vai levar até ele, com ele, estabelece-se uma formação quantitativa, qualitativa e eticamente de excelência. Nessa perspectiva, o professor só se (re)conhece como um bom professor a partir do olhar do outro.

O terceiro enunciado que nos chamou a atenção aponta para a mudança de posição destacada pelo egresso.

Considero que foi uma formação ampla, o que me deslocou de uma posição que valorizava os conteúdos para uma posição de constante indagação sobre o meu fazer e sobre as aprendizagens dos alunos. (Egresso 3)
Esse depoimento nos permite adentrar em uma questão recorrentemente discutida no meio acadêmico, qual seja, a implicação dos sujeitos da aprendizagem. Para Rios (1997, p. 129), "o professor não pode ser qualificado de competente se não tiver também uma visão crítica de por que ensinar, para que ensinar, qual o significado que tem este ensinamento no contexto social do qual se faz parte, de que interesses está a serviço".

Essa visão crítica encontra-se imbricada em uma posição responsiva, fazendo-se presente no diálogo, no sentido abordado por Bakhtin (2010). Nessa perspectiva, fazer-se presente no diálogo não é só escutar, não é só observar, não é só fazer presença, mas, além disso, é replicar, é ter uma compreensão responsiva, é responsabilizar-se pelo outro; é um ato ético. E essa atitude ativa perante a profissão está arraigada à busca de respostas relacionadas aos saberes constituídos e às práticas do cotidiano escolar. Buscar saber "como se realizam 'as respostas responsáveis' é um modo de reencontrar os deslocamentos imperceptíveis na construção continuada dos valores, dos sentidos que regem, mas que se fazem e desfazem na existência." (GERALDI, 2004, p. 289). Nesse sentido, o autor pontua que não há acabamento definitivo a ser perseguido. "Há sempre algo-a-ser-alcançado: o que nos vai dando sentido, direção (nunca reta nem linear) (GERALDI, 2013, p. 19). Assim, estaremos sempre, dialeticamente, sendo constituídos como sujeitos-professores, calculando possibilidades e escolhendo respostas que se nos apresentam como acabamento provisório, pois estamos em um mundo em-processo-de-ser. "E não temos álibi: estamos sempre educando, formal ou informalmente, ainda que seja uma perspectiva negativa e indesejável"(GERALDI, 2013, p. 22).

A partir dessa condição de não álibi, vamos constituindo nossos percursos formativos e a nós mesmos como sujeitos que somos. Desse modo, podemos nos reportar a Moita (1992, p.137), que assevera que "as experiências profissionais não são formadoras per si. É o modo como as pessoas as assumem que as tornam potencialmente formadoras". Assim, a articulação entre educação básica e ensino superior é, dialeticamente, um diálogo entre sujeitos em constituição. 


\section{CONSIDERAÇÕES FINAIS}

Nos limites deste artigo, portanto, sem objetivar dar conta de todas as contribuições propiciadas pelos mestrados profissionais em educação, buscamos evidenciar que a questão que se constitui como uma característica precípua dessa modalidade formativa é a articulação entre o ensino superior e a educação básica. Nesse sentido, ao proceder a um recorte e evidenciar as percepções de egressos acerca das contribuições propiciadas pelo Programa de Mestrado Profissional em Educação (PPGE) da Universidade Federal de Lavras (MG) para a atuação dos egressos na educação básica, buscamos analisar potenciais efeitos dessas percepções para a sistematização de uma reflexão sobre os Mestrados Profissionais.

Com vistas a contextualizar a nossa análise, buscamos, inicialmente, construir uma reflexão acerca da caracterização dos mestrados profissionais em educação, por meio de provocações relacionadas às questões que são basilares para a compreensão das especificidades de uma formação profissional. Desse modo, entendemos que as contribuições trazidas pelos autores estudados ou que constituem nosso campo de investigação propiciaram a potencialização de questões apontadas na citação de Fialho e Hetkowski (2017), que foi tomada como ponto de partida. Tais questões assumem relevância para uma discussão sobre os MPE, em função da diversidade de aspectos contemplados em um excerto que apresenta concisão e profundidade.

Assim, ao analisarmos a responsabilidade atribuída aos mestrados profissionais de responder pela formação profissional de alto nível, consideramos relevante destacar que os MPE possuem bases epistemológicas (relacionadas às diferentes teorias educacionais) e bases axiológicas (concepções e valores relativos às práticas educativas), que, notadamente, iluminam o percurso formativo, seja na proposição dos objetivos relacionados à formação, seja no atendimento das demandas profissionais e/ou institucionais. Imputar responsabilidade aos Programas supõe implicar sujeitos, que precisam (re)significar seus atos pedagógicos e reconstruí-los a partir e por meio de reflexões teórico-práticas, em uma postura assumidamente colaborativa.
Ao pensarmos nos mestrados profissionais como um espaço mobilizador de ações e de iniciativas de articulação com o ambiente profissional e com o mundo do trabalho, destacamos que tomar a prática profissional como objeto de análise significa desestabilizar certezas e reconhecer a condição de inacabamento. Apoiados em Catarino, Barbosa-Lima e Queiroz (2015, p. 840), retomamos a afirmação de que "Somente o que é constante não faz a docência intelectual, é necessário o irrepetível, o evêntico, o único.". Nessa perspectiva, o professor, também sujeito da ação, passa a se perceber único e a se posicionar, "assumindo, então, a responsabilidade: se eu sou insubstituível, devo realizar minha unicidade." (p. 840). O sujeito é responsável por seus atos e tem obrigação ética com relação ao outro. Ao fazê-lo, poderá mobilizar iniciativas que possam circunstanciar uma relação dialética entre teoria e prática. Desse modo, "não é possível ignorar a existência desses outros - aluno, escola, sociedade - no enunciado do professor. Dessa maneira, o outro se constitui como um objeto para o professor intelectual construir sua prática e suas estratégias de ensino, pesquisa e ação num contexto filosófico e político." (p. 840)

A assunção do mundo do trabalho como eixo formativo demanda uma abordagem que contemple o enfrentamento das problemáticas relacionadas à formação de professores e à gestão educacional e escolar. Considerando as especificidades de um curso de mestrado profissional, a partir das discussões empreendidas, podemos reiterar que as atividades realizadas durante o percurso formativo devem viabilizar uma atitude responsiva acerca da ação docente e de situações do contexto escolar, de identificação de situações problemas que podem ser tomadas como objeto de análise e esclarecidas por um processo sistemático de coleta de dados e de referenciais teórico-metodológicos. Nessa direção, reiteramos a posição de André e Princepe (2017, p. 10), de que a "pesquisa quando promove a reflexão crítica sobre a prática profissional em educação possibilita o desenvolvimento de indivíduos críticos e criativos".

Após as discussões sobre as questões que caracterizam os mestrados profissionais, consideramos válido pontuar a per/insistência da articulação entre universidade e escolas de educação básica como um 
elemento basilar para a qualificação dos processos formativos.

Nesse contexto, ao analisarmos os depoimentos apresentados pelos egressos - participantes da pesquisa, embora várias outras dimensões tenham sido contempladas, optamos por fazer um recorte e explorar mais detidamente as respostas. Essa escolha procedimental representa o nosso posicionamento epistemológico de que a formação docente é, necessariamente, a formação de sujeitos, que, por meio de processos interativos - alunos, colegas, pares, sociedade, se constituem como pessoas e como profissionais e se posicionam no mundo e acerca dele.

Nesse sentido, a contribuição deste trabalho se consubstancia na provocação de uma reflexão sobre a efetividade dos Mestrados Profissionais para uma formação, que contemple a docência e a gestão escolar na educação básica, evidenciando um posicionamento que considera que o projeto e as ações formativas dessa modalidade se constituem como práticas sociais, que, por sua vez, promovem a constituição de sujeitos-professores, propiciam a compreensão de processos educativos, ampliam as bases epistemológicas e fortalecem a aproximação entre agências educativas e agentes formadores.

\section{REFERÊNCIAS}

ANDRÉ, M. E. D. A. de. Formar o professor pesquisador para um novo desenvolvimento profissional. In: ANDRÉ, M. E. D. A. de. Práticas inovadoras na formação de professores. Campinas, SP: Papirus, 2016.

ANDRE, M.; PRINCEPE, Lisandra. O lugar da pesquisa no Mestrado Profissional em Educação. Educar em Revista, Curitiba, n. 63, p. 103-117, Mar. 2017. Disponível em: < http://www.scielo.br/scielo.php?script=sci_abstract\&pi$\mathrm{d}=$ S0104=40602017000100103-\&lng=en\&nrm=iso\&tlngpt>. Acesso 02 fev. 2019.

BAKHTIN, M. M. O Homem ao espelho. In: $O$ Homem ao Espelho. Apontamentos dos anos 1940. São Carlos: Pedro \& João Editores, 2019.

BAKHTIN, M. M. Estética da Criação Verbal. Tradução do russo por Paulo Bezerra. São Paulo: WMF Martins Fontes, 2011.

BAKHTIN, M. M. Para uma filosofia do ato responsável. São Carlos: Pedro \& João Editores, 2010.
BRASIL. Ministério da Educação. Portaria normativa no 17, de 28 de dezembro de 2009. Dispõe sobre o mestrado profissional no âmbito da Fundação Coordenação de Aperfeiçoamento de Pessoal de Nível Superior - Capes. Diário Oficial da União, no 248, Brasília, DF, 29 dez. 2009. Seção 1, p. 20-21. Disponível em: Acesso em: 30 mar. 2019.

BRASIL. Ministério da Educação. Fundação Coordenação de Aperfeiçoamento de Pessoal de Nível Superior - Capes Mudanças na ficha de avaliação valorizam a pós-graduação. 2019. Disponível em : <http://portal. mec.gov.br/index.php?option=com_content\&view=article\&id=73911: mudancas-na-ficha-de-avaliacao-valorizam-a-pos-graduacao\&catid $=225 \& \mid$ temid $=86>$. Acesso em: 21 mar. 2019.

CAMPOS, M. A. T.; GUERIOS, E. Mestrado Profissional em Educação: reflexões acerca de uma experiência de formação à luz da autonomia e da profissionalidade docente. Educ. rev., Curitiba, n. 63, p. 35-51, Mar. 2017. Disponível: < http://www.scielo.br/scielo.php?script=sci_arttex-

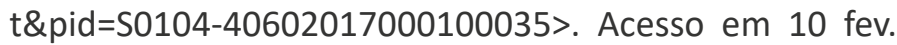
2019.

CATARINO, G. F. C.; BARBOSA-LIMA, M. C. A.; QUEIROZ, G. R. P. C. A prática docente e o dialogismo bakhtiniano: o ensino como um ato responsável. Ciênc. Educ., Bauru, v.21, n.4, p. 835-849, 2015. Disponível: <http://www. scielo.br/pdf/ciedu/v21n4/1516-7313-ciedu-21-04-0835. pdf>. Acesso em 10 fev. 2019.

FIALHO, N. H.; HETKOWSKI, T. M. Mestrados Profissionais em Educação: novas perspectivas da pós-graduação no cenário brasileiro. Educar em Revista., Curitiba, n. 63, p. 19-34, Mar. 2017. Disponível em: < http://www.scielo. br/pdf/er/n63/1984-0411-er-63-00019.pdf>. Acesso 02 fev. 2019.

GATTI, B. Educação, escola e formação de professores: políticas e impasses. Educar em Revista, n. 50, p. 51-67, out./dez. 2013. Disponível em: < http://www.scielo.br/ pdf/er/n50/n50a05.pdf >. Acesso 02 fev. 2019.

GERALDI, J. W. Alteridades: espaços e tempos de instabilidades. In: L. Negri e R. P. de Oliveira (Orgs.). Sentido e significação em torno da obra de Rodolfo llari. São Paulo, SP: Contexto, 2004.

GERALDI, W. Bakhtin tudo ou nada diz aos educadores: os educadores podem dizer muito com Bakhtin. In: FREITAS, M. T. (Org.). Educação, arte e vida em Bakhtin. Belo Horizonte: Autêntica, 2013.

IMBERNÓN, F. Qualidade do ensino e formação do professorado. São Paulo: Cortez, 2016. 
MAGALHÃES, M. C. C.; NININ, M. O. G.; LESSA, Â. B. C. T. A dinâmica discursiva na formação de professores: discurso autoritário ou internamente persuasivo?. Bakhtiniana, Rev. Estud. Discurso, São Paulo, v. 9, n. 1, p. 129-147, July 2014. Disponível em: < http://www.scielo.br/scielo.php?script $=$ sci_arttext \&pid=S2176-45732014000100009>. Acesso em 10 set. 2018.

MARTINS, F. P; LUCAS, M.; MIRANDOLA, C. S. A formação de professoras alfabetizadoras: estratégias formativas na aprendizagem da docência. In: ANDRÉ, M. E. D. A. de. Práticas inovadoras na formação de professores. Campinas, SP: Papirus, 2016.

MOITA, M. C. Percursos de formação e de transformação. In: NÓVOA, A. (Ed.). Vidas de professores. Porto: Porto Editora, 1992. p. 111-140.

RIOS, T. A. Ética e interdisciplinaridade. In: FAZENDA, I. (org.). A pesquisa em educação e as transformações do conhecimento. 2. ed. Campinas: Papirus, 1997. p. 121136.
ROMÃO, J. E.; MAFRA, J. F. Mestrado profissional: crônica de uma morte anunciada. Revista Plurais, Salvador, v. 1, n. 2, p. 10-23, abr./ago. 2016. Disponível em: < https:// www.revistas.uneb.br/index.php/plurais/article/download/2685/1815>. Acesso em 10 set. 2018.

SOBRAL, A. O ato "responsível", ou ato ético, em Bakhtin, e a centralidade do agente. Signum, Londrina, n. 11/1, p. 219-235, jul. 2008.

VOLÓCHINOV, V. N. As mais recentes tendências do pensamento linguístico ocidental. In: $A$ construção da enunciação e outros ensaios. Organização, tradução e notas por João Wanderley Geraldi. Edição e supervisão da tradução por Valdemir Miotello. São Carlos: Pedro \& João Editores, 2013.

VOLÓCHINOV, V.N. Marxismo e Filosofia da Linguagem. Problemas fundamentais do método sociológico na ciência da linguagem. Tradução do russo, notas e glossário por Sheila Grillo e Ekaterina Vólkova Américo. São Paulo: Editora 34, 2017. 